\title{
AVALIAÇÃO DO DOENTE COM DOR CRÔNICA EM CONSULTA DE ENFERMAGEM: PROPOSTA DE INSTRUMENTO SEGUNDO DIAGNÓSTICOS DE ENFERMAGEM
}

\author{
Diná de Almeida Lopes Monteiro da Cruz* \\ Cibele Andrucioli de Mattos Pimenta**
}

\begin{abstract}
CRUZ, D.A.L.M.da; PIMENTA, C.A.de M. Avaliação do doente com dor crônica em consulta de enfermagem: proposta de instrumento segundo diagnósticos de enfermagem. Rev.latino-am.enfermagem, Ribeirão Preto, v. 7, n. 3, p. 49-62, julho 1999.
\end{abstract}

Descreve-se o instrumento de coleta de dados para a avaliação de enfermagem do doente com dor crônica na Liga de Dor do HC-FMUSP, cuja finalidade primordial é identificar as necessidades de cuidados dos doentes. Utilizam-se os diagnósticos de enfermagem propostos pela North American Nursing Diagnosis Association (NANDA) para indicar as necessidades de cuidados. Para auxiliar no raciocínio diagnóstico, a estrutura de Padrões de Respostas Humanas em que os diagnósticos de enfermagem são classificados pela NANDA direcionou a construção do instrumento. Descreve-se também como ele é utilizado pelas alunas de graduação que atuam no serviço.

UNITERMOS: avaliação em enfermagem, diagnóstico de enfermagem, dor

\section{1- INTRODUÇÃO}

Diversos modelos teóricos de enfermagem buscam definir os fenômenos clínicos que são o foco da atuação do enfermeiro, mas não há consenso sobre quais sejam esses fenômenos. Alguns modelos teóricos estão em fase de desenvolvimento, os conceitos não estão articulados, não há indicações de como investigar os fenômenos e não sugerem as intervenções a serem implementadas quando da observação da entidade clínica que se busca atender. Desse modo, a aplicação clínica desses modelos é difícil. No entanto, possuir referenciais teóricos que guiem o ensino, a assistência e a pesquisa na área é fundamental. Não os possuir representa iniciar uma viagem sem saber onde se quer chegar (quais fenômenos clínicos se quer atender) e de que recursos se dispõe para chegar ao local desejado (intervenções). Sem essas balizas há grande chance de se percorrer a trajetória traçada por outros profissionais ou ficar à mercê do acaso.

A responsabilidade de cuidar exige que as decisões sobre as intervenções propostas sejam fundamentadas na avaliação do estado de saúde do doente. É impossível que a avaliação seja totalmente completa, isto é, que nenhum aspecto fique sem exploração total.
Deve-se pensar na coleta de informações como um processo, que pode ser mais ou menos completo, ser realizado em etapas, apresentar maior ou menor grau de especificidade, dependendo do cliente, dos objetivos e filosofia da instituição. A análise sobre a adequação do histórico de enfermagem, nos aspectos de conteúdo e forma, deve considerar as características do serviço e de seus profissionais.

A coleta dos dados deve ser entendida como um ato intencional, realizado para atingir objetivos claramente estabelecidos, em momentos e lugares planejados. A sua sistematização envolve organizar o conteúdo que se pretende buscar e a estrutura seqüencial desse conteúdo, freqüentemente, em históricos padronizados. $\mathrm{O}$ atendimento às condições descritas favorece a obtenção de dados precisos para a formulação de diagnósticos também precisos ${ }^{4}$.

A situação clínica do doente, a natureza das informações que se quer obter e as habilidades cognitivas e perceptivas da enfermeira são fatores que influenciam a organização de modelos para a coleta dos dados ${ }^{4}$. Quando a assistência se dá em unidades especializadas, à esses três elementos, associa-se maior probabilidade de ocorrência e de identificação de determinadas

\footnotetext{
* Enfermeira. Professora Doutora do Departamento de Enfermagem Médico-Cirúrgica da Escola de Enfermagem da Universidade de São Paulo. Coordenadora da Liga de Dor do HC-FMUSP

** Enfermeira. Professora Doutora do Departamento de Enfermagem Médico-Cirúrgica da Escola de Enfermagem da Universidade de São Paulo. Orientadora da Liga de Dor do HC-FMUSP
} 
necessidades de cuidados. Em pacientes que compartilham problemas de saúde semelhantes, a maior probabilidade de ocorrência de certas necessidades de cuidados deve ser usada para nortear o conteúdo da coleta de informações. No entanto, é necessário ter cautela para que isso não se torne fator limitante para a identificação de necessidades pouco freqüentes na população em questão. Cabe ressaltar que a educação formal e informal, a inteligência, o raciocínio lógico, entre outros fatores, e as habilidades afetivas da enfermeira (compromisso, motivação para atender e empatia com o doente) são fundamentais para o uso adequado de qualquer instrumento.

O contexto da coleta dos dados é o processo de enfermagem. É a primeira etapa e serve de base para a identificação dos diagnósticos de enfermagem dos pacientes atendidos. A opção pelo uso dos diagnósticos de enfermagem propostos pela North American Nursing Diagnosis Association (NANDA) na Liga de Dor do Hospital das Clínicas da Faculdade de Medicina da Universidade de São Paulo fundamentou-se no pressuposto de que o uso de linguagem padronizada para expressar as situações clínicas dos doentes pelas quais somos responsáveis favorece o desenvolvimento do raciocínio diagnóstico e também o desenvolvimento de pesquisas sobre intervenções. A classificação da NANDA é ampla, prevê fenômenos clínicos de interesse para a enfermagem nos domínios físico, emocional e social e isso atende a compreensão que se tem de que doente com dor crônica experiência modificações nas áreas biológica, psíquica e na vida de relação.

A Liga de Dor visa a assistência, ensino e pesquisa relacionadas ao tema dor crônica. Destina-se a alunos de graduação de enfermagem e medicina da Universidade de São Paulo, em caráter prioritário e, em segunda instância, a profissionais e estudantes de outras instituições ${ }^{11}$. É atividade extracurricular e voluntária. Os alunos, sob orientação de professores, permanecem na Liga por pelo menos 1 ano, durante 3 a 4 horas semanais. Frente às condições existentes considerou-se especialmente oportuna a implementação dos diagnósticos de enfermagem da NANDA nesse serviço.

Na primeira consulta de enfermagem o doente é avaliado segundo tópicos de histórico de enfermagem padronizado; com os dados obtidos são formulados os diagnósticos e as intervenções são propostas e iniciadas. Nas consultas de enfermagem de retorno, agendadas de acordo com as exigências dos cuidados em andamento, cada paciente é avaliado quanto aos diagnósticos identificados e quanto às respostas às intervenções iniciadas.

O propósito primordial do histórico de enfermagem é obter dados para a identificação dos diagnósticos de enfermagem, vistos como indicativos das necessidades de cuidados dos doentes. A configuração do conteúdo, seqüência e formato do instrumento para coleta dos dados no histórico de enfermagem foi pautada nas seguintes expectativas: favorecer o processo de ensino-aprendizagem de assistência ao doente com dor crônica, tendo como referencial os diagnósticos de enfermagem da NANDA; possibilitar a assistência a doentes com dor crônica de diversas etiologias; adquirir experiência clínica com os diagnósticos de enfermagem da NANDA; possibilitar a obtenção retrospectiva de dados para pesquisas sobre o doente com dor crônica e a inclusão de outros dados, eventualmente necessários para pesquisas prospectivas; ser o mais abrangente possível, não se restringindo somente às situações clínicas mais freqüentemente afetadas em doentes com dor crônica, visando permitir a obtenção de conhecimento relativo à outros fenômenos de enfermagem; servir de guia detalhado dos fenômenos em estudo, favorecendo a condução da avaliação pelos alunos menos experientes; ter conteúdo de fácil compreensão e favorecer o raciocínio diagnóstico.

As características desejadas para a sistematização da coleta de informações na Liga de Dor foram sendo construídas à medida que o trabalho se desenvolveu. Os instrumentos propostos foram se modificando em decorrência de observações de que alguns aspectos poderiam ser aprimorados. De qualquer forma, apesar das seguidas modificações, desde o primeiro instrumento proposto para teste o conteúdo já era organizado segundo os Padrões de Respostas Humanas, que compõem a estrutura de classificação dos diagnósticos de enfermagem da NANDA ${ }^{10}$. Esse é um dos fatores que favorece o raciocínio clínico voltado para a formulação de diagnósticos de enfermagem. Não garante precisão no processo diagnóstico, mas favorece a sua condução ${ }^{2}$.

\section{2- DESCRIÇÃO DO INSTRUMENTO}

O instrumento de coleta de dados consta de três partes: identificação do doente, caracterização do diagnóstico médico e da etiologia da dor compõem a primeira parte; a segunda refere-se aos Padrões de Respostas Humanas. A terceira parte destina-se ao registro de outros dados de interesse clínico, como resultados de exames, impressões do entrevistador, entre outros.

Estudos prévios sobre a freqüência de ocorrência dos diagnósticos de enfermagem em doentes com dor crônica $^{3,13,14}$, ofereceram subsídios para a seleção das áreas que mereciam ser exploradas com maior ou menor aprofundamento. Para o detalhamento do instrumento no que se refere à avaliação da dor e de suas repercussões 
no indivíduo foram utilizados resultados de estudos realizados em nosso meio ${ }^{12,14}$. Outras referências foram consultadas para definir o conteúdo do instrumento necessário à identificação das características definidoras dos diagnósticos de enfermagem e de seus fatores relacionados ${ }^{1,4,6,7,8}$.

\subsection{Dados de identificação}

Os dados dessa parte do instrumento são obtidos junto ao doente e seu acompanhante e do prontuário do doente.

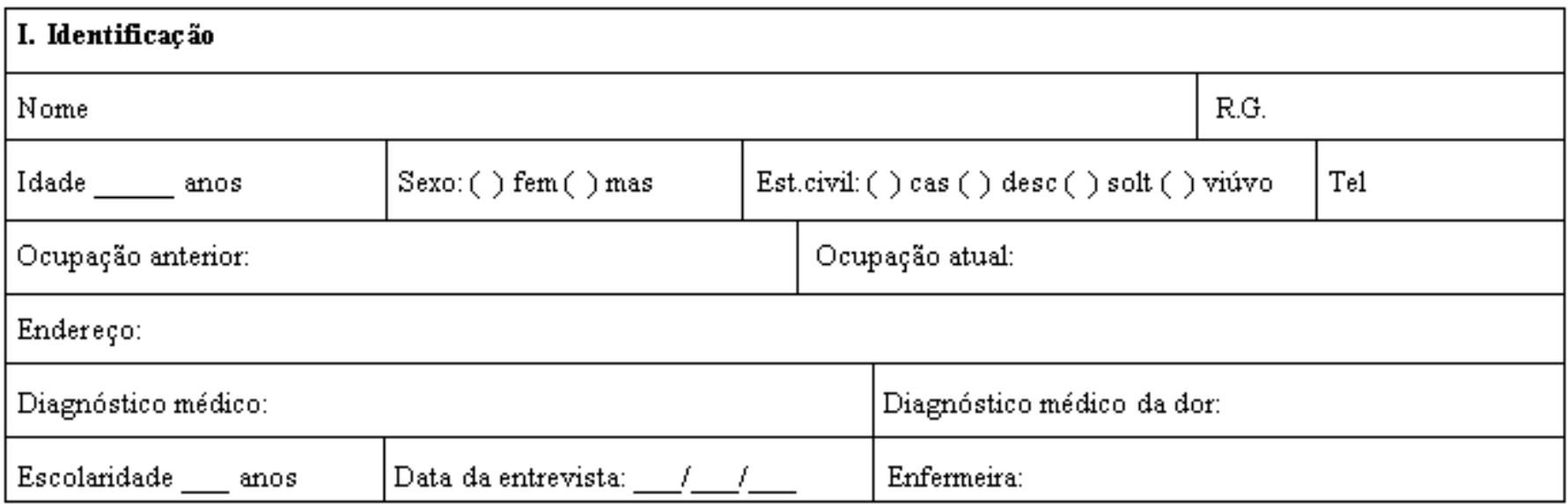

\subsection{Padrões de Respostas Humanas}

Essa parte do instrumento teve seu conteúdo organizado nos Padrões de Respostas Humanas propostos pela NANDA. Os diagnósticos de enfermagem de maior interesse para o doente dor crônica, foram incluídos no padrão pertinente. Junto ao nome do Padrão de Resposta Humana em questão aparece a descrição do foco de sua avaliação e os títulos dos diagnósticos possíveis naquele padrão. Essa foi uma estratégia para auxiliar, especialmente o novato, a associar a entrevista aos objetivos específicos da avaliação de cada padrão. Esperase que o aluno desenvolva habilidade de identificar e seguir 'pistas' altamente relevantes para a identificar ou excluir diagnósticos e também que desenvolva habilidade para abandonar, com segurança, o aprofundamento de qualquer item de avaliação que julgar irrelevante. Nenhum instrumento de coleta de dados será totalmente completo ou totalmente isento de questões eventualmente desnecessárias. Assim, no caso do instrumento que estamos apresentando, há questões para obter dados sobre as necessidades de cuidados mais freqüentes na clientela mas, é a enfermeira/aluna que decide, no decorrer da própria consulta, em que itens é necessário aprofundar a avaliação e em quais é suficiente a informação prevista no instrumento. Como o serviço tem também a finalidade de pesquisa recomenda-se que nenhum item fique sem resposta ou sem o registro da razão pela qual a resposta não consta.

Pela descrição do conteúdo do instrumento observa-se que a avaliação de cada Padrão de Resposta Humana, muitas vezes, se completa com os dados referentes a outro padrão. Isso indica que não há limites claros entre um padrão e outro. Ao interpretar os dados para formular os diagnósticos é necessário que todo o instrumento seja consultado para a busca dos dados relevantes de cada padrão.

Não existe hierarquia entre os padrões de resposta e a seqüência estabelecida no instrumento foi a que nos pareceu melhor para a condução dos assuntos. No entanto, nada impede que a enfermeira/aluna, por alguma razão altere a seqüência proposta e, algumas vezes, é desejável que o faça.

\section{Conhecer}

O conteúdo do instrumento no que se refere à avaliação do Padrão de Resposta - Conhecer tem a finalidade oferecer dados que descrevam o que o doente conhece sobre a sua doença, sobre a dor que sente e sobre o tratamento que faz. Nesse padrão inicia-se a investigação dos dados objetivos e subjetivos sobre as informações que o doente possui sobre sua doença e tratamento, sua capacidade para apreender informações e também sobre o interesse que tem, ou não, em conhecer o que se passa com ele. Quando o doente está acompanhado por seu cuidador ou familiar, cada um individualmente e a interação de ambos devem ser observadas continuamente. Especialmente no Padrão Conhecer, as reações do cuidador ou familiar vão indicar a possibilidade de o paciente não ter sido exposto às informações verdadeiras sobre a sua condição. Esses casos precisam ser explorados porque as informações errôneas ou parciais podem estar relacionadas a diferentes necessidades de cuidados como por exemplo o manejo ineficaz do tratamento, "coping" ineficaz, falta de adesão, interação social prejudicada, desesperança e impotência. 
CONHECER

Identificar características definidoras das respostas do doente sobre o que ele conhece da sua situação de saúde e sobre a capacidade para apreender informações. (Déficit de conhecimento (especificar); Confusão mental; Processo de pensamento prejudicado; Alteração da memória, síndrome da interpretação ambiental prejudicada)

Qual o seu problema de saúde?

Na sua opinião, qual a causa da sua dor

Que tratamento(s) já fez?

Que resultados obteve com esse(s) tratamento(s)?

Quanto ao tratame nto atual:

\begin{tabular}{|l|l|l|l|}
\hline Que remédios utiliza? & Dose & Servem para: & Efeitos colaterais \\
\hline & & & \\
\hline
\end{tabular}

$\mathrm{O}$ que o Sr.(a) espera do tratamento?

Na sua opinião, quanto tempo o tratamento vai durar?

$O$ que gostaria de me perguntar?

Tem dificuldade de aprender coisas novas? () sim

() กão Especifique:

\section{Comunicar}

Os dados obtidos nesse padrão devem permitir descrever a comunicação verbal e o conteúdo da comunicação não-verbal do doente. São especificadas as expressões não-verbais que podem estar presentes na situação de dor e sofrimento. Na dor crônica a expressão não-verbal é pouco específica e, em doentes adultos, com condições de compreensão e verbalização adequadas, o auto-relato é a chave para a afirmação diagnóstica. Nesse padrão também se obtém mais dados sobre as condições do doente para verbalizar, obter e lidar mentalmente com informações, complemento importante para a descrição do Padrão Conhecer.

\section{COMUNICAR}

Identificar características definidoras das respostas do doente relativas a sua comunicação verbal e não verbal (especialmente as expressões não-verbais de dor) (Comunicação verbal prejudicada)

\section{Comunicação verbal}

\begin{tabular}{|c|c|c|c|c|}
\hline Lê? ( ) $\sin ()$ não & Escreve? () sim () não & Inform & detalhes necessários? () sim () não & Prolixo?() $\sin ($ ) não \\
\hline \multicolumn{2}{|c|}{ Mostra clareza na expresão das idéias: ( ) sim } & () กล̃o & Especifique: & \\
\hline
\end{tabular}

\section{Co municação não verbal}

\begin{tabular}{|c|c|c|}
\hline \multicolumn{3}{|c|}{ Expressões não verbais de: } \\
\hline $\begin{array}{l}\text { Sofrimento/Dor( ) sim ( ) não } \\
\text { Especifique: }\end{array}$ & $\begin{array}{l}\text { Tristeza () sim () não } \\
\text { Especifique: }\end{array}$ & $\begin{array}{l}\text { Contrariedade () sim () não } \\
\text { Especifique: }\end{array}$ \\
\hline \multirow[t]{2}{*}{$\begin{array}{l}\text { Choro () sim () não } \\
\text { Especifique: }\end{array}$} & $\begin{array}{l}\text { Contato ocular ( ) } \operatorname{sim}() \text { não } \\
\text { Especifique: }\end{array}$ & $\begin{array}{l}\text { Fácies tranqüila ( ) sim () não } \\
\text { Especifique: }\end{array}$ \\
\hline & $\begin{array}{l}\text { Inquietação() sim () não } \\
\text { Especifique: }\end{array}$ & $\begin{array}{l}\text { Postura de proteção( ) sim () não } \\
\text { Especifique: }\end{array}$ \\
\hline
\end{tabular}


Valorar

No Padrão Valorar buscam-se informações sobre a existência, quais são e a importância de questões espirituais para o doente. Objetiva também identificar em que tipo de situações as questões espirituais ajudam e se são úteis especificamente para o controle da dor.

Durante todo a avaliação é necessário estar atento às informações que indiquem a influência da dor e sofrimento no significado da vida para o doente.

\section{VALORAR}

Identificar características definidoras de respostas do doente relativas a crenças e a valores transcendentais e de como essas respostas dão suporte ou não à vivência e tratamento da dor (Angústia espiritual; Potencial para fortalecimento do bem-estar espiritual)

\begin{tabular}{|l|}
\hline Tem preferência religiosa? () sim () não Especifique: \\
\hline Existem coisas espirituais importantes para o Sr.(a)? () sim () não Especifique: \\
\hline Elas o ajudam?( ) sim () não Em que situações? \\
\hline Elas o ajudam a agüentar a dor? () sim () não Especifique:
\end{tabular}

\section{Relacionar}

O conteúdo das informações relativas ao Padrão Relacionar deve indicar como se compõe a vida de relação próxima do doente, as influências dos relacionamentos na saúde em geral e no manejo da dor em particular. Dados referentes às influências da dor e tratamento nos relacionamentos são investigados nesse conjunto. Indicase, no instrumento, que a enfermeira/aluna, durante a coleta de informações sobre esse padrão observe a interação entre o doente e seu familiar/cuidador, caso este o esteja acompanhando, e que atenção especial seja dada para a observação do conhecimento e reações do cuidador às funções que tem desempenhado. Estimula-se a participação do cuidador nas atividades de orientação coletiva e nas consultas individuais. Se, durante estas atividades, observa-se alguma necessidade específica do cuidador, avaliação e orientação mais dirigidas são organizadas.

\section{RELACIONAR}

Identificar características definidoras de respostas do doente referentes a suas interações sociais, afetivas e desempenho de papéis. Poderia incluir a avaliação da dinâmica familiar e do cuidador. (Isolamento social; Interação social prejudicada; Risco para solidão; Disfunção sexual; Alteração nos processos familiares; "Esgotamento" do cuidador; Risco de "esgotamento" do cuidador)

\begin{tabular}{|l|}
\hline Com quem vive? \\
\hline Quem mais o ajuda no seu tratamento? \\
\hline Sente-se satisfeito com a ajuda que recebe? () sim () não Por que? \\
\hline Sente-se sozinho com freqüência? () sim ( ) não Por que? \\
\hline OBSERWAÇÕES sobre a interação familiar e o cuidador (durante a entrevista pela enfermeira) \\
\hline
\end{tabular}

\section{Sentir}

Esse é o padrão que tem maior número de itens a serem avaliados. É nele que se classificam os diagnósticos de dor e dor crônica. Além de guiar a busca dos dados para caracterizar a dor, o instrumento, nesse padrão, também direciona para a obtenção de informações à respeito das reações do doente às perdas reais e percebidas, bem como os sentimentos de ansiedade e medo. Para compor a avaliação das características da dor foram incluídos itens sobre o local da dor mais importante para o doente e os locais e intensidades das outras dores que porventura tenha. Sobre a dor mais importante para o doente exploram-se mais detalhadamente: tempo de dor, intensidade (escala numérica e de descritores verbais), forma de início, horário de ocorrência, situações que exacerbam e atenuam a dor. Para a descrição das qualidades da dor utiliza-se o Questionário de Dor McGill $^{9}$ adaptado para a língua portuguesa ${ }^{12}$. Informações advindas de outros padrões também fornecem dados que completam a avaliação da dor quando, por exemplo, se pede ao doente que relate algum comportamento pertinente ao padrão em estudo, analisando-o dentro do contexto da vivência dolorosa. A vivência de dor crônica, freqüentemente, resulta em perdas econômicas, prejuízos 
na vida de relação, nas atividades de vida diária e laborativas, em alteração do humor, mudanças no sono e no apetite e em sentimentos de frustração, ansiedade e medo. A investigação desses aspectos nos diferentes padrões fornece dados sobre o impacto da dor na vida do indivíduo.

\section{SENTIR}

Identificar características definidoras de respostas do doente relativas as interpretações de estímulos, eventos e situações do ambiente (Dor, Dor crônica, Pesar disfuncional, Pesar antecipado, Ansiedade, Medo)

Dor

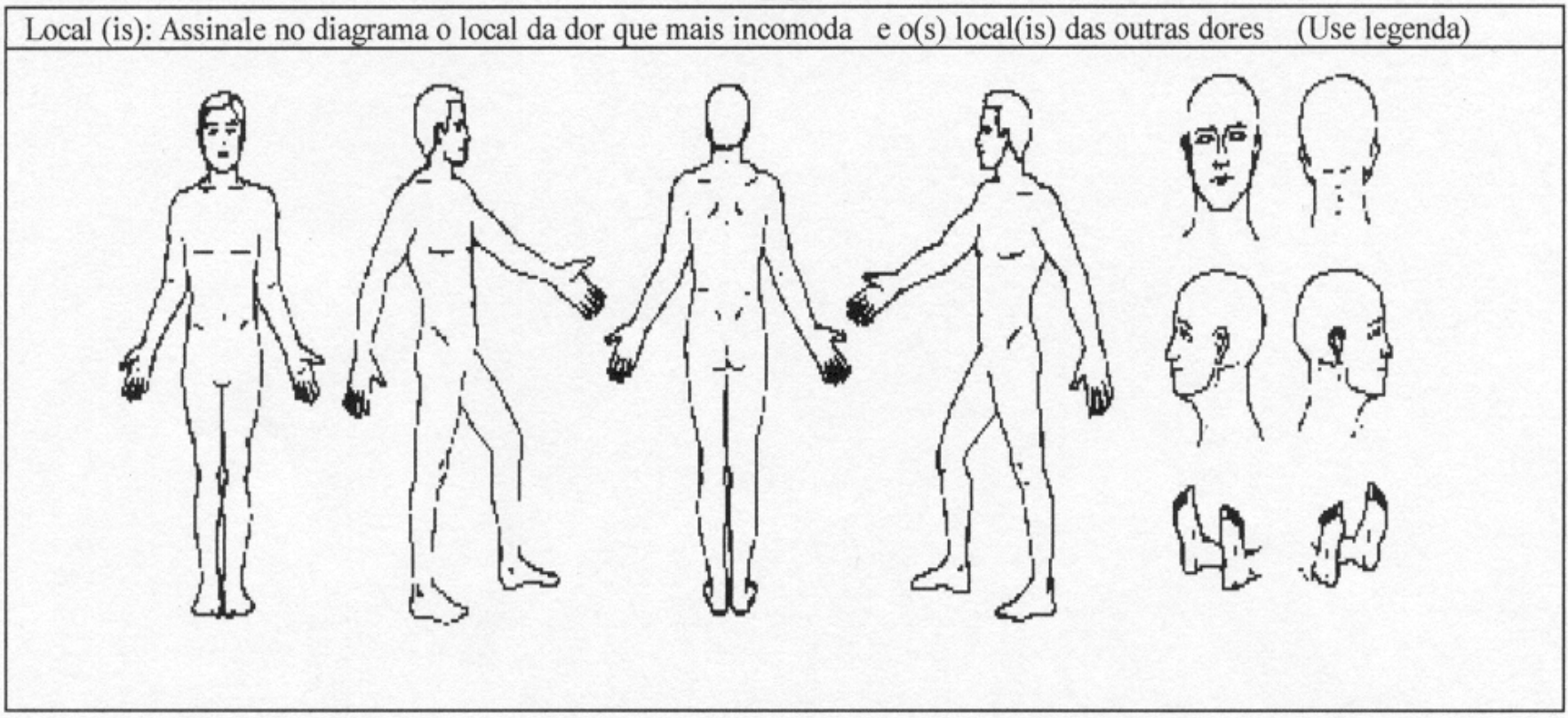

Legenda: Dor que mais incomoda (marque um sinal de + )

Outras dores (marque L1, L2, L3 etc.)

Fonte: MCCAFFERY; Beebe. Pain; Clinical Manual for Nursing Practice. Mosby: St Louis, 1989. p. 21 (permitida reprodução)

\section{SOBRE A DOR QUE MAIS INCOMODA}

Há quanto tempo sente essa dor?

Está com dor agora? ( ) sim ( ) não Se não, quando sentiu dor pela última vez? Há dias

Intensidade (0-10): $\quad($ ) leve ( ) moderada ( ) intensa ( ) insuportável

Ela: ( ) é contínua ( ) via e vem independente de qualquer coisa ( ) vai e vem dependendo de

A dor tem: ( ) início súbito ( ) início insidioso

A dor tem horário preferencial? ( ) sim ( ) não Qual?

O que faz essa dor melhorar?

O que faz essa dor piorar?

\section{SOBRE OUTRAS DORES}

Local 1 (L1)

intensidade $(0-10)$ qualidade:
Local 2 (L2)

intensidade $(0-10)$ qualidade: 
INVENTÁRIO PARA AVALIAÇÃO DA DOR McGRILL (dor que mais incomoda)

Algumas das palavras que eu vou ler descrevem a sua dor atual (aquela que mais o incomoda). Diga-me quais palavras melhor descrevem a sua dor. Não escolha aquelas que não se aplicam. Escolha somente uma palavra de cada grupo, a mais adequada para a descrição da sua dor.

\begin{tabular}{|c|c|c|c|c|c|c|}
\hline Sub-categ. & & & SENSORIAL & - DESCRITO & & \\
\hline 1 & 1 vibração & 2 tremor & 3 pulsante & 4 latejante & 5 como batida & 6 como pancada \\
\hline 2 & 1 pontada & 2 choque & 3 tiro & & & \\
\hline 3 & 1 agulhada & 2 perfurante & 3 facada & 4 punhalada & 5 em lança & \\
\hline 4 & 1 fina & 2 cortante & 3 estraçalha & & & \\
\hline 5 & 1 beliscão & 2 aperto & 3 mordida & 4 cólica & 5 esmagamento & \\
\hline 6 & 1 fisgada & 2 puxão & 3 em torção & & & \\
\hline 7 & 1 calor & 2 queimação & 3 fervente & 4 em brasa & & \\
\hline 8 & 1 formigamento & 2 coceira & 3 ardor & 4 ferroada & & \\
\hline 9 & 1 mal localizada & 2 dolorida & 3 machucada & 4 doída & 5 pesada & N. de desc. \\
\hline 10 & 1 sensível & 2 esticada & 3 esfolante & 4 rachando & & Soma pontos \\
\hline Sub-categ. & & & AFETIVO - & DESCRITOR & & \\
\hline 11 & 1 cansativa & 2 exaustiva & & & & \\
\hline 12 & 1 enjoada & 2 sufocante & & & & \\
\hline 13 & 1 amedrontadora & 2 apavorante & 3 aterrorizante & & & \\
\hline 14 & 1 castigante & 2 atormenta & 3 cruel & 4 maldita & 5 mortal & N. de desc. \\
\hline 15 & 1 miserável & 2 enlouquecedora & & & & Soma pontos \\
\hline Sub-categ. & & & AVALIATIVO & - DESCRITO & & \\
\hline 16 & 1 chata & 2 que incomoda & 3 desgastante & 4 forte & 5 insuportável & N. de desc. \\
\hline & & & & & & Soma pontos \\
\hline Sub-categ. & & & MISCELÂNEA & - DESCRITC & & \\
\hline 17 & 1 espalha & 2 irradia & 3 penetra & 4 atravessa & & \\
\hline 18 & 1 aperta & 2 adormece & 3 repuxa & 4 espreme & 5 rasga & \\
\hline 19 & 1 fria & 2 gelada & 3 congelante & & & N. de desc. \\
\hline 20 & 1 aborrecida & 2 dá náusea & 3 agonizante & 4 pavorosa & 5 torturante & Soma pontos \\
\hline
\end{tabular}

TOTAL

Número de descritores escolhidos

Soma dos pontos das subcategorias

O Sr. se sente nervoso/tenso com freqüência? ( ) sim ( ) não Especifique:

O Sr. sente medo ou receio de algo? ( ) sim ( ) não Especifique:

ATENTAR PARA VERBALIZAÇÕES que indiquem reações de pesar (como lida com as perdas percebidas, ou com a antecipação delas ): 


\section{Perceber}

Os itens para a avaliação do Padrão Perceber referem-se ao autoconceito e autopercepção do doente e a influência da situação de saúde nesses aspectos da sua vida. Devese buscar identificar a atitude do doente frente à dor, o quanto de controle percebe ter sobre a situação, o quanto ter ou não controle é importante para ele e se atribui a outrem ou a algo significativa parcela de controle. É também nesse padrão que se busca descrever, na perspectiva do doente, como ele vê seu futuro e o quanto realista é essa perspectiva. Este Padrão de Resposta depende muito da habilidade e experiência da enfermeira/ aluna para a obtenção de dados válidos e relevantes. Apesar de os diagnósticos relativos à percepção sensorial estarem classificados no padrão perceber, no presente instrumento a investigação desses dados está prevista no Padrão Trocar. Essa decisão fundamentou-se no fato de que incluir essa avaliação no Padrão Perceber provocaria descontinuidade de conteúdo na situação da coleta dos dados.

\section{PERCEBER}

Identificar características definidoras de respostas relativas a auto-percepção, auto-conceito e à percepção sensorial (Distúrbio da imagem corporal; Distúrbio da auto-estima; Alterações senso-perceptivas; Desesperança; Impotência) Mover

Como o Sr.(a) descreveria seu modo de ser?

Gostaria de ser diferente? ( ) sim ( ) não Especifique

A doença modificou o seu jeito de ser? ( ) sim ( ) não Especifique

Que planos o Sr.(a) tem para o futuro?

Na sua opinião o Sr.(a) pode ajudar no tratamento da dor? ( ) sim ( ) não Por que?

O Sr.(a) sente-se disposto a participar no seu tratamento? ( ) sim ( ) não Por que?

\begin{tabular}{|c|c|c|c|c|c|c|}
\hline $\begin{array}{c}\text { Quanto o Sr.(a) pode ser ajudado no seu } \\
\text { tratamento: }\end{array}$ & Muito & Pouco & Quase nada & Nada & Não sei & Observações \\
\hline por si mesmo & & & & & & \\
\hline pela sua família & & & & & & \\
\hline pela pessoa que mais o ajuda & & & & & & \\
\hline pelo médico & & & & & & \\
\hline pela enfermeira & & & & & & \\
\hline pela psicóloga & & & & & & \\
\hline por Deus & & & & & & \\
\hline pela sorte & & & & & & \\
\hline
\end{tabular}

\begin{tabular}{|c|c|c|c|c|}
\hline O Sr.(a) se sente doente? & ( ) não & ( ) um pouco & ( ) muito & ( ) totalmente \\
\hline Tolerar a dor é & ( ) muito fácil & ( ) fácil & ( ) difícil & ( ) muito difícil \\
\hline O Sr.(a) se sente útil? & ( ) sim, muito útil & ( ) $\operatorname{sim}$, mas não muito & ( ) pouco útil & ( ) não, nada útil \\
\hline $\begin{array}{l}\text { A atenção e o afeto que recebe são } \\
\text { suficientes para suas necessidades? }\end{array}$ & $\begin{array}{l}\text { ( ) sim, totalmente } \\
\text { suficiente }\end{array}$ & $\begin{array}{l}\text { ( ) sim, mas pouco } \\
\text { suficiente }\end{array}$ & $\begin{array}{l}\text { ( ) não, gostaria de } \\
\text { receber mais afeto }\end{array}$ & $\begin{array}{l}\text { ( ) totalmente } \\
\text { insuficiente }\end{array}$ \\
\hline $\begin{array}{l}\text { O Sr.(a) está preocupado ou ansioso } \\
\text { sobre sua doença? }\end{array}$ & ( ) não & ( ) um pouco & ( ) muito & ( ) totalmente \\
\hline Sua vida é satisfatória? & $\begin{array}{l}\text { ( ) sim, muito } \\
\text { satisfatória }\end{array}$ & $\begin{array}{l}\text { ( ) sim, um pouco } \\
\text { satisfatória }\end{array}$ & $\begin{array}{l}\text { ( ) não, não é } \\
\text { satisfatória }\end{array}$ & $\begin{array}{l}\text { ( ) totalmente } \\
\text { insatisfatória }\end{array}$ \\
\hline
\end{tabular}


Nesse item do instrumento figuram perguntas cujas respostas permitem descrever o sono, a atividade física, a mobilidade corporal total e de partes do corpo e os hábitos de lazer dos doentes. É no conteúdo da avaliação desse padrão que se insere a avaliação da dependência/independência do doente para as atividades de vida diária. É importante que se procure descrever o dia típico do doente com dor crônica no que se refere ao Padrão Mover, visto que algumas intervenções poderão exigir alterações nesse padrão, ou que a sua modificação pode se constituir em estratégias para melhor manejo e alívio da dor.

MOVER

Identificar características definidoras de respostas relativas à mobilidade do corpo ou de partes corporais; à capacidade para realizar atividades de cuidado pessoal independentemente; ao padrão de sono, repouso e lazer, e tolerância às atividades

Escolher

\section{Sono}

Quando acorda se sente disposto para as atividades do dia? ( ) sim ( ) não Por que?

Quantas horas dorme por dia?

Tem dificuldade para conciliar o sono? ( ) sim ( ) não Por que?

Há interrupções no sono? ( ) sim ( ) não Quantas vezes por noite?

O que interrompe o seu sono?

\section{Atividade/mobilidade física}

Sente que sua energia é suficiente para as atividades que gostaria de fazer? ( ) sim ( ) não Por que?

Das atividades que vou mencionar indique se as faz sozinho ou se precisa de ajuda:

\begin{tabular}{|l|l|l|l|}
\hline \multicolumn{1}{|c|}{ Atividades: } & Faz sozinho & $\begin{array}{c}\text { Depende da ajuda de } \\
\text { outra pessoa }\end{array}$ & $\begin{array}{c}\text { Depende totalmente de } \\
\text { outra pessoa }\end{array}$ \\
\hline alimentar-se & & & \\
\hline ir ao banheiro & & & \\
\hline tomar banho & & & \\
\hline vestir-se & & & \\
\hline caminhar & & & \\
\hline & & & \\
\hline
\end{tabular}

Existem dificuldades para a vida do dia a dia? ( ) sim ( ) não Especifique
Como o Sr.(a) passa a maior parte do dia?

( ) sentado

( ) deitado

( ) em atividade física

( ) distribui o tempo entre repouso e atividades físicas

Tem alguma limitação para movimentar alguma parte do corpo?

( ) $\operatorname{sim}$

( ) não

Especifique:

\section{Recreação}

O que faz para se distrair?

Sente que essa(s) atividade(s) o distrai(em)? ( ) sim ( ) não Por que?

Há algo que gostaria de fazer e que não pode? Especifique

O comportamento usual do doente quando se vê em situações difíceis é explorado nesse padrão. Apesar de a avaliação ser genérica, a enfermeira/aluna deve conduzir o doente a relatar os seus comportamentos 
quando sente dor. Isto é, se a dor caracteriza uma situação problemática para o doente, é necessário investigar que estratégias para lidar com a dor ele utiliza (estratégias de enfrentamento), identificar os comportamentos e pensamentos que freqüentemente ele tem quando a dor aparece ou se intensifica. Na seqüência, interessa saber que resultados ele obtém com as estratégias que usa. Pedese também ao doente que indique as área da sua vida em que a doença ou tratamento trouxe ou traz problemas e como está lidando com eles. Os dados obtidos nesse padrão são importantes para se identificar comportamentos para controle da dor que devam ser desestimulados, aqueles que devem ser reforçados e outros que podem ser ensinados. Estas informações contribuem para avaliar se a atitude do doente favorece ou não a adesão ao tratamento e seu manejo.

\section{ESCOLHER}

Identificar características definidoras relativas às estratégias para lidar com situações difíceis e seus resultados incluindo as estratégias relativas ao manejo do problema de saúde (Coping individual ineficaz; Ajustamento prejudicado; Falta de adesão (especificar); Manejo ineficaz do tratamento; Conflito de decisão)

\begin{tabular}{|l|}
\hline Quando o Sr.(a) se sente nervoso o que faz para aliviar? \\
\hline Quando tem problemas em sua vida como procura resolvê-los? \\
\hline O Sr.(a) está satisfeito com a forma com que lida com os problemas que tem? ( ) sim ( ) não \\
\hline Tem dificuldade para tomar decisões? ( ) sim $\quad$ ( ) não Por que? \\
\hline Quando a dor vem em que o Sr.(a) pensa? \\
\hline Quando a dor vem o que o Sr.(a) faz para ajudar a agüenta-la ou melhora-la? \\
\hline O que mais o ajuda a agüentar a dor? \\
\hline O Sr.(a) consegue fazer o que os médicos e enfermeiras lhe recomendaram? ( ) sim $\quad$ ( ) não Especifique
\end{tabular}

\section{A doença trouxe algum problema}

\begin{tabular}{|l|l|}
\hline no seu trabalho? ( ) sim ( ) não Especifique \\
\hline nos seus estudos? ( ) sim ( ) não Especifique \\
\hline no seu relacionamento familiar? ( ) sim $\quad$ ( ) não $\quad$ Especifique \\
\hline no seu relacionamento sexual? ( ) sim ( ) não Especifique \\
\hline no seu lazer? ( ) sim $\quad$ ( ) não Especifique \\
\hline financeiro? ( ) sim ( ) não $\quad$ Especifique \\
\hline no relacionamento com outras pessoas além da família? ( ) sim $\quad$ ( ) não Especifique \\
\hline O que o senhor fez ou está fazendo para lidar com isso?
\end{tabular}

\begin{tabular}{|l|l|l|l|l|l|}
\hline O Sr.(a) costuma: & Nunca & Poucas vezes & Muitas vezes & $\begin{array}{c}\text { No passado costumava, mas } \\
\text { agora não mais }\end{array}$ & Observações* \\
\hline beber bebidas alcoólicas & & & & & \\
\hline fumar cigarros comuns & & & & & \\
\hline fumar maconha & & & & & \\
\hline usar drogas (cocaína, crack etc) & & & & & \\
\hline xingar/brigar & & & & & \\
\hline chorar & & & & & \\
\hline bater na mesa/quebrar coisas & & & & & \\
\hline
\end{tabular}

\footnotetext{
* Especificar as circunstâncias - especialmente se ocorrem quando tem dor
} 


\section{Trocar}

Os diagnósticos classificados nesse padrão são predominantemente os relacionados às respostas físicas aos problemas de saúde. Alterações alimentares, de eliminação intestinal e urinária são freqüentes em doentes em tratamento de dor crônica o que justifica maior detalhamento dos dados. Quanto a outras áreas, investigase junto ao doente a presença ou não de alterações respiratórias, circulatórias, de pele, de sensibilidade, alterações de temperatura corporal, entre outras. Investiga-se também a presença de alterações relacionadas aos órgãos do sentido.

\section{TROCAR}

Identificar características definidoras de respostas referentes às funções do corpo, ao metabolismo como troca de energia (Alterações nutricionais; Risco de infecção; Alterações da temperatura do corpo; Obstipação; Diarréia; Incontinência intestinal, incontinência urinária; Retenção urinária; Alterações de volumes de líquidos; Trocas gasosas prejudicadas; Eliminação traqueobrônquica ineficaz; Padrão respiratório ineficaz; Risco para trauma; Risco para aspiração; Risco para prejuízo na integridade da pele; Integridade da pele prejudicada; Proteção alterada.

Nutrição - Hidratação

\begin{tabular}{|l|l|l|l|}
\hline Apetite ( ) conservado $\quad$ ( ) diminuído & ( ) melhorado & \multicolumn{2}{l|}{ Quantas refeições o Sr.(a) faz por dia? } \\
\hline Houve mudanças recentes no seu peso? ( ) sim & ( ) não & Quantos Kg? & Em quanto tempo? \\
\hline Houve alteração de paladar? ( ) sim & ( ) não & Descreva: \\
\hline Segue alguma dieta especial? ( ) sim & ( ) não & Qual? \\
\hline
\end{tabular}

Com que freqüência o Sr.(a) ingere os seguintes alimentos

\begin{tabular}{|l|l|l|l|l|}
\hline \multicolumn{1}{|c|}{ Alimentos } & Diariamente & $2-3$ vezes por semana & Raramente & Observações \\
\hline grãos (feijão, arroz etc) & & & & \\
\hline massas (pão, macarrão) e doces & & & & \\
\hline carnes/ovos/leite & & & & \\
\hline verduras e legumes & & & & \\
\hline Frutas & & & & \\
\hline
\end{tabular}

Quantos copos de líquido o Sr.(a) ingere por dia? (considere: água, leite, café, sucos, refrigerantes etc)

\section{Eliminação intestinal}

Ostomia? ( ) sim ( ) não

Freqüência das evacuações: $\mathrm{x} / \mathrm{dia}$ ou $\mathrm{x} /$ semana. Especifique se houve alterações recentes:

Fezes: ( ) pastosas ( ) endurecidas ( ) líquidas ( ) em síbalas

Desconfortos para evacuar: ( ) dor ( ) sangramento ( ) sensação de reto cheio ( ) exteriorização de hemorróidas ( ) nenhuma Uso freqüente de ( ) laxantes ( ) lavagens ( ) outras manobras ( ) nenhum Especifique

\section{Eliminção urinária}

Freqüência das micções $\mathrm{x} /$ dia. Especifique se houve alterações recentes

Cor da urina: ( ) normal ( ) alterada Especifique

Cheiro da urina: ( ) normal ( ) alterada Especifique

Quantidade nas 24 horas: ( ) mantida ( ) aumentada ( ) diminuída

Desconfortos urinários: ( ) dor ( ) sangramento ( ) urgência ( ) perda involuntária de urina ( ) retenção urinária ( ) nenhum
( ) diminuição de volume por micção
( ) aumento da freqüência 
O Sr.(a) tem alguma das seguintes condições

\section{Respiração}

\begin{tabular}{|l|c|c|l|}
\hline tosse & ( ) sim & ( ) não & \\
\hline secreção & $($ ) sim & ( ) não & \\
\hline falta de ar & $($ ) sim & ( ) não & \\
\hline & $($ ) $\operatorname{sim}$ & ( ) não & \\
\hline
\end{tabular}

\section{Circulação}

\begin{tabular}{|l|c|c|l|}
\hline problema de coração & ( ) sim & ( ) não & \\
\hline pressão alta & ( ) sim & ( ) não & \\
\hline edema & ( ) sim & ( ) não & \\
\hline & $($ ) sim & ( ) não & \\
\hline
\end{tabular}

\section{Temperatura}

\begin{tabular}{|l|c|c|l|}
\hline febre & ( ) sim & ( ) não & \\
\hline alguma parte do corpo com temperatura diferente & ( ) sim & ( ) não & \\
\hline & ( ) sim & ( ) não & \\
\hline
\end{tabular}

\section{Pele}

\begin{tabular}{|l|c|c|l|}
\hline lesão & ( ) sim & ( ) não & \\
\hline mancha & $($ ) $\operatorname{sim}$ & ( ) não & \\
\hline & $($ ) sim & ( ) não & \\
\hline
\end{tabular}

\section{Uso de artefatos}

Há alterações de: ( ) visão ( ) audição ( ) olfação ( ) gustação ( ) nenhum

Há alguma região do corpo que a sensibilidade da pele é alterada? ( ) sim ( ) não ( ) hipoestesia ( ) anestesia ( ) disestesia ( ) alodínea

Especifique

Gostaria de perguntar alguma coisa?

Em que gostaria de ser ajudado?

\subsection{Dados Complementares}

Essa parte do instrumento é espaço aberto para a enfermeira/aluna registrar outros dados que considere necessários para a adequada interpretação dos dados coletados nos padrões, como informações do prontuário, resultados laboratoriais, impressões do entrevistador e dados de exame físico. A avaliação fundamenta-se basicamente nos dados de entrevista. O exame físico deve ser feito de acordo com as queixas do doente e os dados coletados na entrevista indicam a necessidade de aprofundá-lo. 
III. Dados complementares: (dados de prontuário, dados laboratoriais, impressões do entrevistador e dados de exame físico)

\section{CONSIDERAÇÕES FINAIS}

O instrumento, tal como descrito, está sendo utilizado na Liga de Dor - HCFMUSP desde abril de 1997. É sem dúvida um instrumento longo, cuja aplicação exige, aproximadamente, 1 hora, dependendo das condições do doente e da experiência da enfermeira/aluna. Ao final da consulta, quando é realizada pela aluna de enfermagem, os dados coletados são discutidos com as enfermeiras orientadoras da Liga de Dor. É o momento de se esclarecer, validar, complementar as informações obtidas e, junto com a aluna, estabelecer os diagnósticos de enfermagem, em caráter preliminar. Nesse momento são também definidas as condutas a serem iniciadas. $\mathrm{O}$ doente é orientado sobre as propostas de enfermagem, estabelecem-se em conjunto, metas a serem alcançadas e é agendado o retorno. Até o retorno seguinte do doente a aluna deve rever e discutir com as orientadoras os dados, confirmando ou não os diagnósticos preliminares e identificando em que áreas a avaliação deve ser retomada ou aprofundada para esclarecer a situação. Em cada retorno do doente é possível acrescentar confirmações ou dúvidas acerca dos diagnósticos firmados na primeira consulta. Este exercício do raciocínio diagnóstico permite estreitar as possibilidades de erros. Trabalhar com diagnóstico é lidar com a incerteza. Como escreveu GORDON $^{5}$ só afirmamos um diagnóstico quando o grau de incerteza para fazê-lo é tolerável.

$\mathrm{O}$ uso dos diagnósticos de enfermagem como referencial metodológico para o atendimento ambulatorial a doentes com dor crônica tem possibilitado caracterizálos sob o ponto de vista da enfermagem. Identificam-se os diagnósticos mais freqüentes e, dessa forma, as áreas prioritárias para a pesquisa sobre intervenções de enfermagem também emergem. Os diagnósticos deixam mais claras as lacunas no conhecimento que fundamenta a profissão. Produzir e articular conhecimentos que permitam fundamentar a prática de enfermagem, no que se refere ao processo de afirmação diagnóstica e na seleção das intervenções a serem utilizadas, depende da identificação das lacunas existentes. Vontade e esforços coordenados permitirão calcar em bases mais sólidas a profissão.

Oferecer ao aluno de graduação a possibilidade de coletar e interpretar os dados do doente tendo como referência os diagnósticos de enfermagem tem sido experiência gratificante. Quando expressamos as necessidades de cuidados em termos de diagnósticos parece que colocamos em relevo, em destaque, a necessidade de cuidado de enfermagem do doente. Sem esta possibilidade, o aluno que ainda não teve a oportunidade de progredir no desenvolvimento do raciocínio clínico e adquirir conhecimentos que fundamentem a interpretação dos dados coletados, pode se ver perdido num terreno repleto de informações e dados aos quais, muitas vezes, não consegue atribuir significado clínico. Conduzir o desenvolvimento do raciocínio clínico, sem o qual não é possível atuação profissional reflexiva, nos parece um grande desafio no ensino da enfermagem.

\section{EVALUATION OF PATIENTS WITH CHRONIC PAIN IN NURSING CONSULTATIONS: PROPOSAL OF AN INSTRUMENT ACCORDING TO NURSING DIAGNOSES}

This article describes the tool used to collect data for nursing evaluation of patients with chronic pain patient in the League Against Pain of the University of São Paulo at Ribeirão Preto Faculty of Medicine, Brazil. The aim is to identify the patients' nursing care needs. The nursing diagnoses proposed by the North American Nursing Diagnosis Association (NANDA) were used to point out the patients' nursing care needs. The Human Response Patterns, in which the nursing diagnoses are classified by NANDA, were used as a framework to construct the tool. The way it is used by nursing undergraduate students, members of the League Against Pain, is also described.

\section{VALORACIÓN DEL ENFERMO CON DOLOR CRÓNICO EN LA CONSULTA DE ENFERMERÍA: PROPUESTA DE INSTRUMENTO SEGÚN DIAGNÓSTICOS DE ENFERMERÍA}

Es descrito un instrumento de valoración de enfermería para pacientes con dolor crónico de la Liga de Dolor - Hospital Clínicas de la Universidad de São Paulo - Brasil. La finalidad del instrumento es identificar necesidades de cuidado de esos pacientes. Son utilizados los diagnósticos de enfermería propuestos por la North American Nursing Diagnosis Association (NANDA) para indicar las necesidades de cuidado. La estructura de Patrones de Respuesta Humana en que los diagnósticos de enfermería son clasificados por la NANDA direccionó la construcción del instrumento. También es descrito cómo el instrumento es utilizado por las alumnas de pre-grado que actúan en el servicio. 
REFERÊNCIAS BIBLIOGRÁFICAS

01. CARPENITO, L.J. Nursing diagnosis: application to clinical practice. 6. ed. Philadelphia: Lippincott, 1995.

02. CRUZ, D.A.L.M. A introdução do diagnóstico de enfermagem no ensino: sua influência no processamento de informações pelo aluno de graduação. São Paulo, 1995.149p. Tese (Doutorado) - Escola de Enfermagem, Universidade de São Paulo.

03. CRUZ, DALM.; PIMENTA, C.A.M.; MARTINS, L.M.M. Perfil do doente com dor crônica. In: SIMPÓSIO INTERNACIONAL DE DOR, 2., São Paulo, 1995. Programa. São Paulo, 1995. p.25.

04. GORDON, M. Nursing diagnosis: process and application. 3.ed. Saint Louis: Mosby, 1994.

05. GORDON, M. Nursing diagnosis: process and application. Saint Louis: Mosby, 1982.

06. GORDON, M. Manual of nursing diagnosis 19971998. St. Louis: Mosby, 1997.

07. GUZZETTA, C.; BUNTON, S.D.; PRINKEY, L.A.; SHERER, A. Clinical assessment tools for use with nursing diagnoses. St. Louis: Mosby, 1989.
08. McFARLAND, G.K.; McFARLANE, E.A. Nursing diagnosis $\&$ intervention: planning for patient care. 2.ed. Saint Louis: Mosby,1993.

09. MELZACK, R. The McGill pain questionnaire: major properties and scorin methods. Pain, v.1, n.1 p.277-299, 1975.

10. NORTH AMERICAN NURSING DIAGNOSIS ASSOCIATION. Nursing diagnoses: definitions \& classification. (1997-1998). Philadelphia: NANDA, 1996.

11. PIMENTA, C.A.M. et al. Liga de dor: uma experiência de ensino extracurricular. Rev.Esc.Enfermagem USP, 1998. /prelo/

12. PIMENTA, C.A.M.; TEIXEIRA, M. J. Questionário de dor McGill: proposta de adaptação para a língua portuguesa. Rev.Esc.Enfermagem USP, v.30, n.3, p.473-83, 1996.

13. PIMENTA, C.A.M.; CRUZ, D.A.L.M. Câncer e dor: alterações nos padrões de resposta humana. Acta Paul.Enfermagem, v.7, n.1, p.27-34, 1994.

14. PIMENTA, C.A.M.; TEIXEIRA M.J. Avaliação da dor. Rev.Med., v.76, n.1, p. 27-35, 1997. (Edição especial). 